\title{
Evaluation of Combined Effects of Vitamin $E$ and Methylprednisolone in Ischemia and Reperfusion Injury of the Testicle Post Torsion and Detorsion in West African Dwarf Goats
}

\author{
Udegbunam Sunday Ositadinma ${ }^{1}$, Okoro Emmanuel Ikechukwu', \\ C. Onuba Augustine ${ }^{1}$, Okereke Henry Nnamdi', Udegbunam Rita ljeoma', \\ Ekere Samuel Okezie², Ezeobialu Toochukwu Henry ${ }^{1}$
}

10.18805/IJAR.B-1309

\begin{abstract}
Background: To investigate the protective effects of vitamin $E$ and methylprednisolone on ischemia and reperfusion testicular injury after testicular torsion and detorsion in West African dwarf (WAD) goats.

Methods: Thirty-two male WAD goats were randomly allocated into four groups $(n=8)$; group $A$ was treated with vitamin $E$, group $B$ with methylprednisolone, group $C$ with combo-therapy of vitamin $E$ and methylprednisolone and group $D$ was the control. The levels of malondialdehyde (MDA), superoxide dismutase (SOD), glutathione (GSH), total tissue protein (TTP) and catalase (CAT) were assayed while tissue biopsies were harvested for evaluation of degeneration of germinal cells, desquamation in germinal cells, interstitial edema and haemorrhage.

Result: Findings revealed that Vitamin E administered immediately post ligature application significantly $(p<0.05)$ decreased MDA level in groups A and C. Vitamin E monotherapy and its combination with methylprednisolone respectively ameliorated more the cellular damage and histological alterations caused by ischaemia and reperfusion injury. This study, therefor, suggests that vitamin $\mathrm{E}$ monotherapy and its combination with methylprednisolone is more beneficial in the management of short and long term ischemia/ reperfusion injury respectively.
\end{abstract}

Key words: Ischaemia, Methylprednisolone, Reperfusion, Testes, Vitamin E.

\section{INTRODUCTION}

Reperfusion injury is a pathophysiologic event that occurs following detorsion of a torsioned tissue or organ (AbdelRahman et al. 2016). Torsion/detorsion according to Alper et al. (2016) brings about biochemical and morphological changes that are mediated by ischemia and reperfusion injury of the tissue. The changes brought about by the reperfusion injury are associated with extreme production of reactive oxygen species (ROS) as well as reactive nitrogen species (RNS) (Filho et al. 2004). Modulation of this oxidative stress changes induced by tissue reperfusion can go a long way in preventing tissue or organ damages resulting from torsion/detorsion (Alper et al. 2016).

Several experimental studies have been done on the effects of some agents in the management of damages resulting from reperfusion injury. Among these agents include, sildenafil which is a phosphodiesterase-5 (PDE-5) inhibitors developed for erectile dysfunction (Abdel-Rahman et al. 2016). L. Carnitine which is an ammonium compound biosynthesized from the amino acid lysine and methionine and sold as international supplements (Reaven, 1995). Others include ascorbic acid (vitamin C), a-tocopherol (vitamin E) (Gasperetto et al. 2005) and methylprednisolone a glucocorticold (Alper et al. 2016). Combined anti-inflammatory and anti-oxidant therapy using methylprednisolone and vitamin $C$ respectively in ischemia and reperfusion injury in rat ovary has been studied (Alper et al. 2016).
1Department of Veterinary Surgery, Faculty of Veterinary Medicine, University of Nigeria Nsukka, Nigeria.

${ }^{2}$ Veterinary Obstetrics and Reproductive Disease, Faculty of Veterinary Medicine, University of Nigeria Nsukka, Nigeria.

Corresponding Author: Okereke Henry Nnamdi, Department of Veterinary Surgery, Faculty of Veterinary Medicine, University of Nigeria Nsukka, Nigeria. Email: nnamdi.okereke@unn.edu.ng

How to cite this article: Ositadinma, U.S., Ikechukwu, O.E., Augustine, C.O., Nnamdi, O.H., ljeoma, U.R., Okezie, E.S., Henry, E.T. (2021). Evaluation of Combined Effects of Vitamin $E$ and Methylprednisolone in Ischemia and Reperfusion Injury of the Testicle Post Torsion and Detorsion in West African Dwarf Goats. Indian Journal of Animal Research. DOI: 10.18805/IJAR.B-1309.

Submitted: 27-07-2021 Accepted: 06-08-2021 Online: 18-09-2021

Vitamin $E$ is a fat soluble anti-oxidant that is essential for the maintenance of healthy skin. As a non-enzymatic anti-oxidant, Vitamin E primarily reacts with ROS (Salvemini et al. 1999). In addition, Vitamin $\mathrm{E}$ also absorbs the energy from ultraviolet (UV) light and thus, plays important role in photo-protection, preventing UV-induced free radical damage to the skin. It also displays some related antiinflammatory activities in the skin (Reaume et al. 1996).

Methylprednisolone which is a potent anti-inflammatory which also acts as an anti-oxidant and membrane stabilizer by reducing migration of macrophages and neutrophils to 
Evaluation of Combined Effects of Vitamin E and Methylprednisolone in Ischemia and Reperfusion Injury of the Testicle...

inflammatory site. It also reduces lipid peroxidation, hydrolytic enzymes release and production of oxy-radicals. (Silvka and Murphy, 2001).

The aim of this study was to evaluate the combination effects of Vitamin $E$ and methylprednisolone on management of reperfusion injury of testicle of West African Dwarf (WAD) goats.

\section{MATERIALS AND METHODS Ethics}

Research studies were carried out in conformity with the National Institutes of Health revised guidelines for laboratory animals' care and use (NIH, 1985) and the University of Nigeria ethical codes and regulations for animal use.

\section{Experimental animals}

A total of thirty-two (32) WAD male goats weighing between $4.2 \mathrm{~kg}-7.5 \mathrm{~kg}$ were used for the study. During acclimatization, they were housed in a clean pen. Grass (alfalfa) supplemented with commercial poultry pellet feed (Top ${ }^{\circledR}$ feed) and water were provided ad libitum for a period of 14 days. This study was carried out in the University of Nigeria, Nsukka, which spanned between the months of June to October 2019.

\section{Methods}

\section{Surgical procedure}

The scrotal regions of each goat in all the groups were aseptically prepared for surgery and anaesthesized by local infiltration of lignocaine hydrochloride $(20 \mathrm{mg} / \mathrm{kg})$ through the tissue of the scrotum along the proposed line of incision. A $2 \mathrm{~cm}$ longitudinal incision was made on the scrotum parallel to the median raphe, cutting through the skin, subcutaneous tissue, spermatic fascia and the entire spermatic cord of the right testis encased in parietal vaginal tunic were twisted and ligated with silk suture $(2 / 0)$ to generate ischemia while the spermatic cord of animals in group $D$ which was the control were neither twisted nor ligated.

Following the ligation, the testicles were replaced into the scrotal sac and sutured with silk suture (2/0) using simple interrupted suture pattern. Four hours post ligation, testicular ligatures were removed to allow reperfusion to take place.

\section{Experimental design}

Immediately after ligation, four goats from each group were treated as follows; group A were treated with vitamin $E$ injection (400 IU/ml, Kwality Pharmaceuticals, India) at the dose of $3.7 \mathrm{IU} / \mathrm{kg}$ intra muscular (i.m), group B treated with methylprednisolone injection (DEPO-MEDROL® $40 \mathrm{mg} / \mathrm{ml}$, Pfizer Belgium) at the dose of $1 \mathrm{mg} / \mathrm{kg}$ i.m, group $\mathrm{C}$ treated with the combination of vitamin $\mathrm{E}(3.7 \mathrm{IU} / \mathrm{kg} \mathrm{i.m})$ and methylprednisolone (1 mg/kg i.m). Animals in group $D$ were neither ligated nor treated.

Immediately post removal of the ligatures, four goats, one each from groups $A, B$ and $C$ were treated as in post ligature application.

\section{Sample collection}

The samples were collected on two different intervals. Firstly, the right testicle of those goats treated, immediately the ligatures were applied and were harvested 4 hours post removal of the ligatures while in the second interval, the right testicles of the goats treated, immediately the ligatures were removed and were harvested 24 hours post removal. At the end of harvests, the right testicle from three goats in each treated groups and three goats from the control group (untreated) were cleaned and washed twice with ice-cold normal saline, homogenized in chilled phosphate buffered saline (PBS) and then centrifuged at $3000 \mathrm{rpm}$ for 15 minutes. The supernatants were obtained and stored at $-20^{\circ} \mathrm{C}$ for biochemical analysis which includes Malondialdeyde (MDA) as described by Jain et al. (1989), superoxide dismutase (SOD) by Magwere et al. (1997), Catalase (CAT) by Aebi et al. (1983), glutathione (GSH) by Flohe and Gunzler, (1984) and total tissue protein (TTP) as described by Lowery et al. (1951).

Histologically, right testicles of two goats from each group of $A, B, C$ and $D$ were used to study the following pathologic lesions: degeneration of germinal cells, reduction in germinal cell counts, disorganization and desquamation in germinal cells and interstitial edema.

\section{Data analysis}

Statistical analysis was performed using Graph Pad Prism 5 software (GraphPad software, San Diego, CA, USA). Results were expressed as mean \pm standard deviation (SD) and all statistical comparisons were made by means of the one-way ANOVA test followed by Tukey test post hoc analysis. Probability value of $p<0.05$ was considered significant.

\section{RESULTS AND DISCUSSION}

The levels of MDA were significantly $(p<0.05)$ different between groups. The control group, group $D(9.17 \pm 02(\mu \mathrm{mol} /$ $\mathrm{kg}$ protein) had the lowest MDA in this study while group $\mathrm{B}$ had the highest MDA level. However by 24 hour post ligature removal, the MDA level of group $C(28.22 \pm 0.01$ ( $\mu \mathrm{mol} / \mathrm{kg}$ protein) became significantly $(p<0.05)$ the lowest when compared with the treated groups (Table 1 ).

The SOD activities were significantly $(p<0.05)$ different between groups. Post application of ligature, group D significantly $(p<0.05)$ showed the highest SOD activity followed by group A. However post ligature removal, group $C$ showed significantly $(p<0.005)$ highest SOD activity when compared with other treated groups (Table 2).

Post application of ligature, group $C$ had significantly $(p<0.05)$ lower CAT values when compared with other groups while in post ligature removal group B CAT value was significantly $(p<0.05)$ the lowest when compared with other groups (Table 3 ).

Post application of ligature and post ligature removal the GSH levels of group B were significantly $(p<0.05)$ lower than other groups (Table 4). 
Evaluation of Combined Effects of Vitamin E and Methylprednisolone in Ischemia and Reperfusion Injury of the Testicle...

TTP value recorded from post application ligature and post ligature removal showed that group B was significantly $(p<0.05)$ the lowest when compared with other groups whereas group $D$ had significantly $(p<0.05)$ highest values compared to other groups (Table 5).

Ischemia is inadequate tissue perfusion due to reduction in blood flow, depletion of energy stored by cells and accumulation of toxic metabolites with the overall consequences of cell death (Alper et al., 2016). Reperfusion

Table 1: MDA ( $\mu \mathrm{mol} / \mathrm{kg}$ protein) levels of different groups post application of ligature and post ligature removal.

\begin{tabular}{lcc}
\hline & $\begin{array}{c}\text { Post application } \\
\text { of ligature }\end{array}$ & $\begin{array}{c}\text { Post ligature } \\
\text { removal }\end{array}$ \\
\hline A & $15.08 \pm 0.00^{\mathrm{a}}$ & $27.20 \pm 0.40^{\mathrm{a}}$ \\
B & $28.72 \pm 0.01^{\mathrm{b}}$ & $30.16 \pm 0.03^{\mathrm{b}}$ \\
C & $27.36 \pm 0.01^{\mathrm{c}}$ & $28.22 \pm 0.01^{\mathrm{c}}$ \\
D & $9.17 \pm 0.02^{\mathrm{d}}$ & $9.17 \pm 0.02^{\mathrm{d}}$ \\
\hline
\end{tabular}

Different superscript ${ }^{a, b, c, d}$ in a column indicate significant difference between groups at the level of probability $(p<0.050)$.

Table 2: SOD levels of different groups post application of ligature and post ligature removal.

\begin{tabular}{lcc}
\hline & $\begin{array}{c}\text { Post application } \\
\text { of ligature }\end{array}$ & $\begin{array}{c}\text { Post ligature } \\
\text { removal }\end{array}$ \\
\hline A & $145.66 \pm 0.01^{\mathrm{a}}$ & $133.78 \pm 0.40^{\mathrm{a}}$ \\
$\mathrm{B}$ & $139.24 \pm 0.02^{\mathrm{b}}$ & $130.23 \pm 0.01^{\mathrm{b}}$ \\
$\mathrm{C}$ & $141.18 \pm 0.03^{\mathrm{c}}$ & $136.90 \pm 0.04^{\mathrm{c}}$ \\
$\mathrm{D}$ & $180.21 \pm 0.02^{\mathrm{d}}$ & $180.21 \pm 0.02^{\mathrm{d}}$ \\
\hline
\end{tabular}

Different superscript $\mathrm{a}, \mathrm{b}, \mathrm{c}, \mathrm{d}$ in a column indicate significant difference between groups at the level of probability $(p<0.05)$.

Table 3: CAT levels of different groups post application of ligature and post ligature removal.

\begin{tabular}{lcc}
\hline & $\begin{array}{c}\text { Post application } \\
\text { of ligature }\end{array}$ & $\begin{array}{c}\text { Post ligature } \\
\text { removal }\end{array}$ \\
\hline A & $20.12 \pm 0.01^{\mathrm{a}}$ & $11.18 \pm 0.03^{\mathrm{a}}$ \\
B & $16.09 \pm 0.02^{\mathrm{b}}$ & $8.12 \pm 0.01^{\mathrm{b}}$ \\
C & $18.43 \pm 0.03^{\mathrm{c}}$ & $15.99 \pm 0.01^{\mathrm{c}}$ \\
D & $32.84 \pm 0.06^{\mathrm{d}}$ & $32.84 \pm 0.06^{\mathrm{d}}$ \\
\hline
\end{tabular}

Different superscript ${ }^{a, b, c, d}$ in a column indicate significant difference between groups at the level of probability $(p<0.05)$.

Table 4: GSH levels of different groups post application of ligature and post ligature removal.

\begin{tabular}{lcc}
\hline & $\begin{array}{c}\text { Post application } \\
\text { of ligature }\end{array}$ & $\begin{array}{c}\text { Post ligature } \\
\text { removal }\end{array}$ \\
\hline A & $22.45 \pm 0.02^{\mathrm{a}}$ & $9.15 \pm 0.04^{\mathrm{a}}$ \\
$\mathrm{B}$ & $12.05 \pm 0.03^{\mathrm{b}}$ & $8.13 \pm 0.02^{\mathrm{b}}$ \\
$\mathrm{C}$ & $17.55 \pm 0.01^{\mathrm{c}}$ & $13.90 \pm 0.04^{\mathrm{c}}$ \\
$\mathrm{D}$ & $25.20 \pm 0.02^{\mathrm{d}}$ & $25.20 \pm 0.02^{\mathrm{d}}$ \\
\hline
\end{tabular}

Different superscript a, b, c, d in a column indicate significant difference between groups at the level of probability $(p<0.05)$.
Table 5: TTP levels of different groups post application of ligature and post ligature removal.

\begin{tabular}{lcc}
\hline & $\begin{array}{c}\text { Post application } \\
\text { of ligature }\end{array}$ & $\begin{array}{c}\text { Post ligature } \\
\text { removal }\end{array}$ \\
\hline A & $26.00 \pm 0.42^{\mathrm{a}}$ & $10.78 \pm 0.02^{\mathrm{a}}$ \\
$\mathrm{B}$ & $14.88 \pm 0.04^{\mathrm{b}}$ & $8.11 \pm 0.01^{\mathrm{b}}$ \\
C & $19.80 \pm 0.10^{\mathrm{c}}$ & $22.81 \pm 0.03^{\mathrm{c}}$ \\
D & $30.10 \pm 0.04^{\mathrm{d}}$ & $30.10 \pm 0.04^{\mathrm{d}}$ \\
\hline
\end{tabular}

Different superscript $a, b, c, d$ in a column indicate significant difference between groups at the level of probability $(p<0.05)$.

injury is increase in blood flow post ischemia which induces oxidative stress via formation of large amount of oxygen and nitrogen derived free radicals thereby causing further damage in the ischemic tissue (Abdel-Rahman et al. 2016).

Organs/tissues that are good candidates for ischemia/ reperfusion injuries are ovaries, kidney, heart, brain intestine, liver and testicle (Alper et al. 2016). Testicular torsion and detorsion as recorded by Karaguzel (2014) causes biochemical and morphological changes in the testicular tissue resulting from the oxidative stress.

In the present study, we observed that the group that received vitamin $E$ alone had significantly lower MDA level when compared with methylprednisolone administration alone or its combination with vitamin $\mathrm{E}$. Mammalian testes as documented by Hekimoglu et al. (2009) are very sensitive to oxidative stress and particularly to lipid peroxidation because of high concentration of poly-unsaturated fatty acids in the plasma membrane. It is documented that a decrease in blood flow during ischemia results into hypoxia which causes elevated levels of lipid peroxidation products such as lactic acid, hypoxanthine and thiobarbituric acid reactive products in ischemic tissue (Akcoora et al. 2008). Akcoora et al. (2008) also stated that increase in blood flow after ischemia leads to deposition of large amount of oxygen and or nitrogen-derived free radicals thereby causing further damage in the ischemic tissue via oxidative stress. The lower level of lipid peroxidation seen in group $A$ is a protective property which reduces free radical attack by neutralizing free radicals before they could cause lipid oxidation or DNA damage. This finding was in agreement with the reports of Colombo et al. (2010) stating that by reducing the free radical attack, antioxidation breaks the chain reaction of lipid peroxidation thereby protecting the cell membrane via lipid repair and replacement.

The decrease in MDA level obtained from goats treated immediately post ligature removal with combination of vitamin $\mathrm{E}$ and methylprednisolone which was statistically significant when compared with goats treated with methylprednisolone alone is also in agreement with the very works of Osmanagaoglo et al. (2012) stating that methylprednisolone alone and vitamin C during histopathological evaluation of the rat ovary, decreased the ischemia /reperfusion injury. 
The significant increase in the levels of SOD, CAT, GSH and TTP in vitamin $E$ treated goats which were also higher when compared with MDA level obtained from the same vitamin $E$ treated goats immediately post application of ligature could be attributed to its antioxidant effects preventing some detrimental factors like DNA damage, inhibition of protein synthesis, corruption of the sperm formation cycle and abnormal spermatogenisis caused by ischemia and perfusion injuries in testicular torsion and detorsion (Maxwell, 1995; Hekimoglu et al., 2009). The findings is in agreement with the works of Abdel-Rahman et al. (2016) who studied the reducible effects of sildenafil on ischemia/perfusion testicular injury post torsion/detorsion in rats.

Conversely, the decreased level of SOD, GSH, CAT and TTP obtained from goats treated with methylprednisolone monotherapy and its combination with vitamin E immediately post application of ligature in comparison with the MDA level of the two treatment groups as seen in this study agrees with the report of Salmasi et al. (2005) whose work on effect of combined anti-inflammatory and antioxidant therapy on ischemia/perfusion injury in rat ovary showed lower level of MDA, CAT and SOD in groups given combination therapy (prednisolone +vitamin C). It is also worthy to note in this study that SOD, GSH, CAT and TTP level of the goats with methylprednisolone alone and vitamin $\mathrm{E}$ combination post ligature removal were significantly higher than the values obtained from groups treated with only vitamin $E$ or methylprednisolone monotherapy. The finding is also in agreement with the works of Koupparis et al. (2005) who reported that the use of the combotherapy of methylprednisolone and vitamin $E$ was more effective in the long term ischemic injury. This feet achieved by the combination could be attributed to drug synergism which might have potentiated the activity of the anti-inflammatory and antioxidant compounds. Slivka and Murphy (2001) also documented that they aid in reduction of lipid peroxidation, hydrolytic enzyme release and production of oxy-radicals which are also the primary and beneficial role of antioxidants in wound healing process.

Histopathological examination of testicular tissue from goats exposed to testicular ischemia via application of ligature revealed degeneration, disorganization and desquamation of germinal cells in goats treated immediately post application of the ligature (Fig 1). Severe hemorrhages were in vitamin $E$ monotherapy and vitamin $E$ and methylprednisolone combotherapy (Fig 1-Plate A; Fig 2Plate $B$ ). Reduction of sperm cells in the lumen were also observed in vitamin $E$ monotherapy and vitamin $E$ and methylprednisolone combotherapy (Fig 2-Plates $\mathrm{A}$ and $\mathrm{C}$ ). For the goats treated immediately post ligature removal, the histopathological examination of testicular tissue revealed moderate to mild degeneration, reduction, disorganization and desquamation of germinal cells in goats treated with monotherapy of vitamin $E$ and methylprednisolone respectively (Fig 3 ) while those goats treated with the combotherapy revealed moderate degeneration, reduction, disorganization and desquamation of germinal cells (Fig 3). These findings showed that combined therapy of vitamin $\mathrm{E}$ and methylprednisolone applied post ligature removal
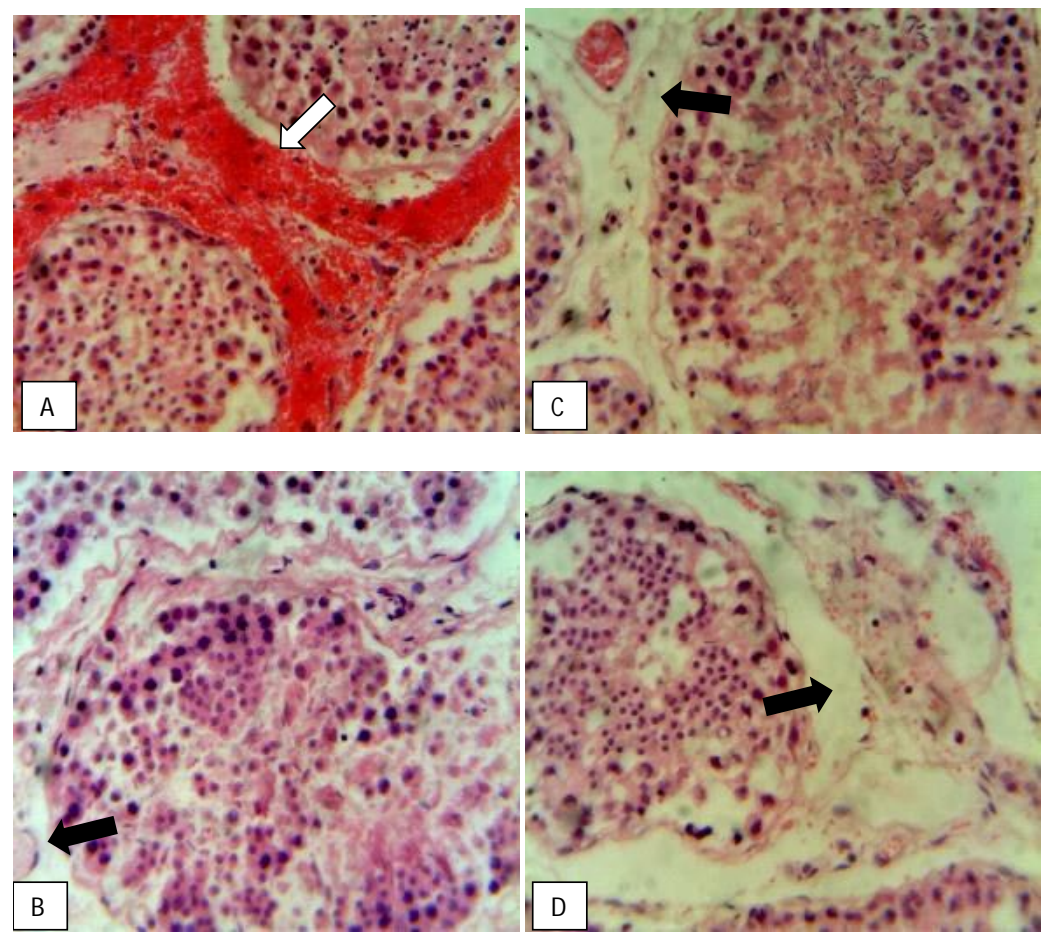

Fig 1: Photomicrographs of the testis from groups $A, B, C$ and $D$ pre-treated before torsion showing desquamation of germinal cells and severe hemorrhage (white arrows) in $A$ and mild interstitial edema (black arrows) in $B, C$ and D. H\&E x400. 

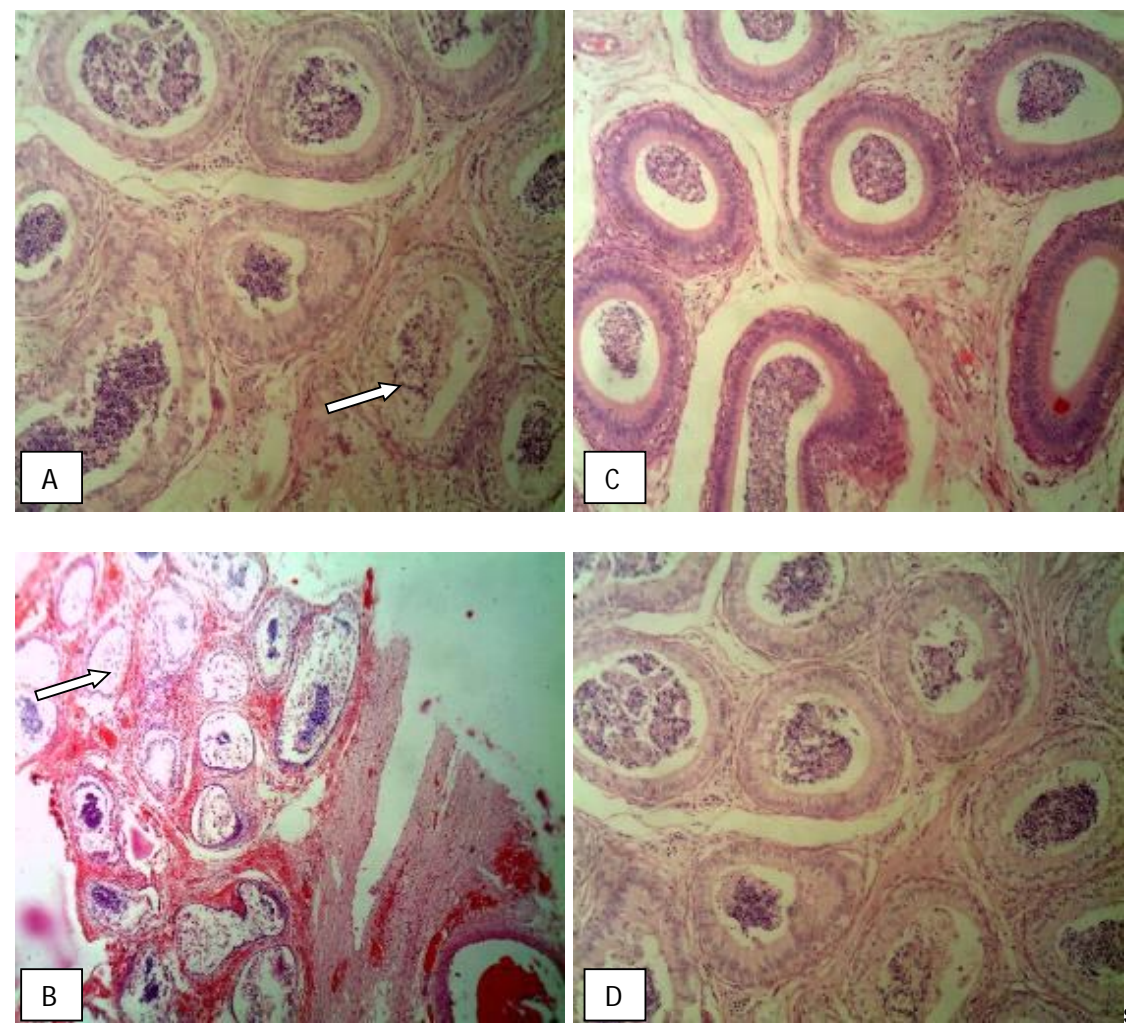

Fig 2: Photomicrographs of the epididymis from groups $A, B, C$ and $D$ pre-treated before torsion necrosis and reduction of sperm cells in the lumen in A and B (white arrows). $H \& E \times 400$.
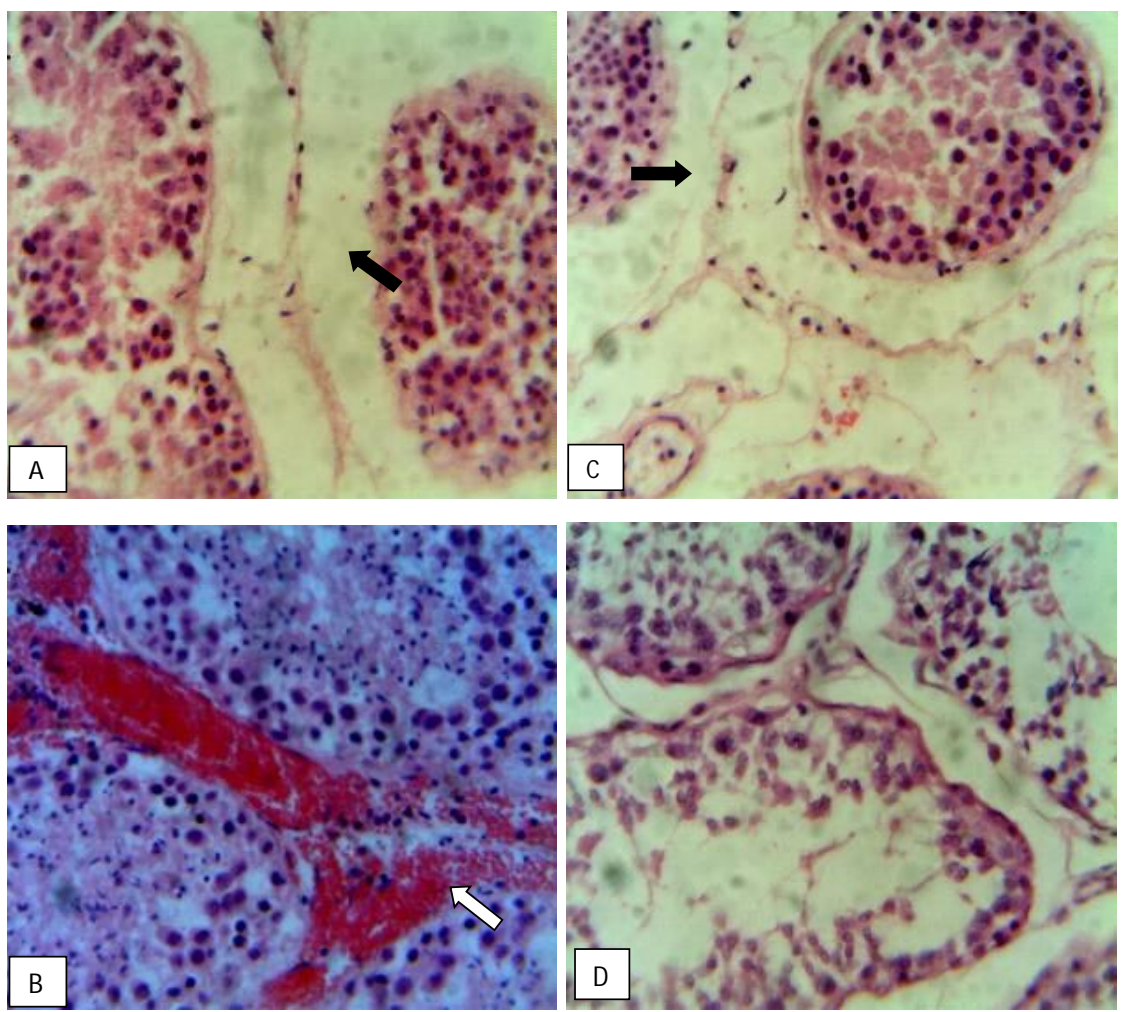

Fig 3: Photomicrographs of the testis from groups $A, B, C$ and $D$ treated after torsion showing severe interstitial edema (black arrows) in $A$ and $C$ but hemorrhages in $B$ (white arrows) while the testicular histo-architecture in $D$ is intact. $H \& E \times 400$. 

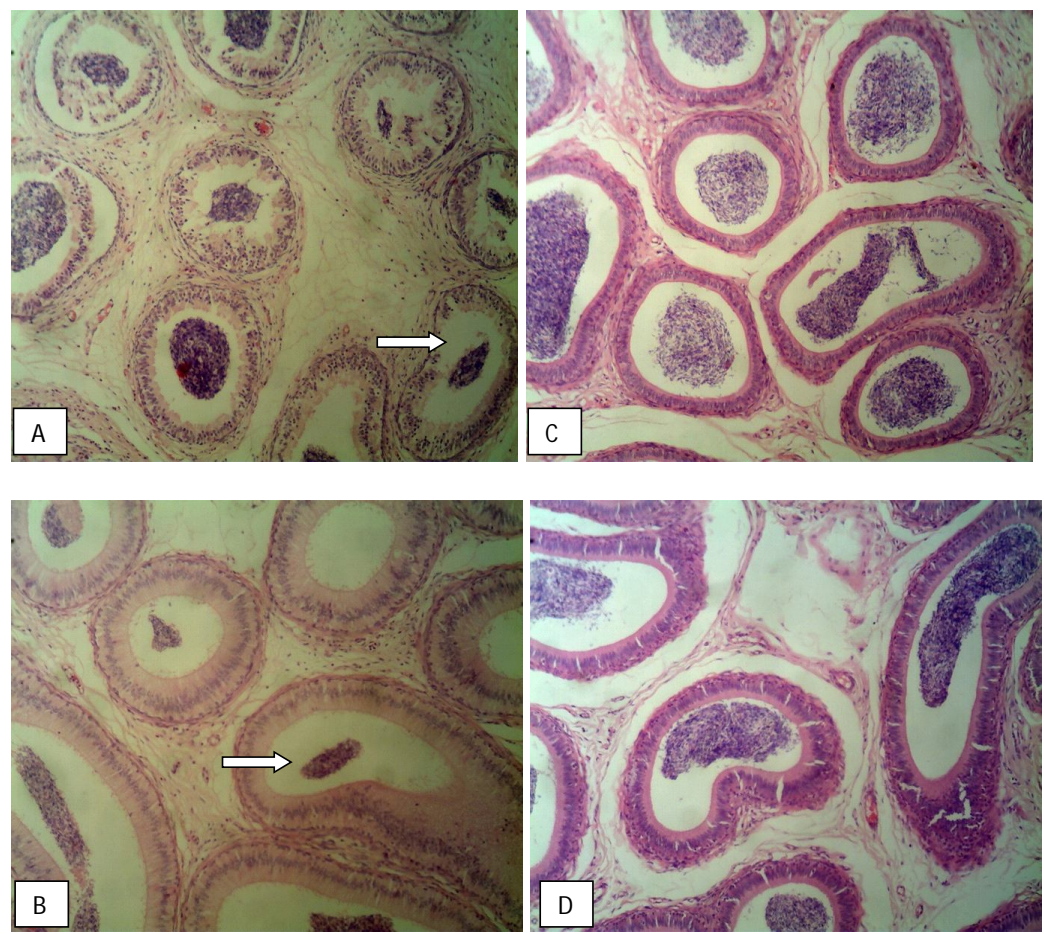

Fig 4: Photomicrographs of the epididymis from groups $A, B, C$ and $D$ treated after torsion showing necrosis and reduction of sperm cells in the lumen in $A$ and $B$ (white arrows) compared to $B$ and $D$. $H \& E \times 400$.

Table 6: Summary of histopathological effects as seen post ligature application.

\begin{tabular}{lcccc}
\hline & Experimental groups & Group B & Group C & Group D \\
Lesions & + & + & + & + \\
\hline Degeneration of geminal cells & + & + & + & - \\
Reduction of germinal cell numbers & + & + & + & - \\
Disorganisation of germinal cells & + & + & + & + \\
Desquamation of germinal cells & + & ++ & + \\
Interstitial EDEMA & +++ & + & + \\
Haemorrhage & ++ & + & + \\
Reduction in epididymal sperm cell reserve & & & + \\
\hline
\end{tabular}

Normal (-), mild (+), moderate $(++)$, severe $(+++)$

ameliorated more the tissue damage caused by ischemia/ perfusion injury in the testis of WAD goats in comparison to monotherapy of vitamin $\mathrm{E}$ or methylprednisolone (Fig 4). The severe interstitial edema shown by vitamin $\mathrm{E}$ monotherapy and methylprednisolone monotherapy as against mild interstitial edema seen in combination therapy immediately post ligature removal gave credence to the efficacious nature of combined therapy of vitamin $E$ and methylprednisolone in long term ischemia as it concurs with the findings of Maxwell (1995).

In conclusion, administration of vitamin $E$ is more beneficial than administration of methylprednisolone or its combination with vitamin $E$ in the management of short term ischemia and perfusion injury of testicles of goats as demonstrated by decrease in the MDA level and increase in the level of SOD CAT, GSH and TTP of the treated goats. Combotherapy of methylprednisolone and vitamin $\mathrm{E}$ post detorsion was more effective in the management of long term ischemia and perfusion injury as demonstrated by its higher level of SOD CAT, GSH and TTP among treatment groups.

\section{REFERENCES}

Abdel-Rahman, M.M., Mahmoud, A.M., Mostafa, N.M., Saleh, E. and Eissa, H.M. (2016). Sildenafil reduces ischemia/ perfusion testicular injury after torsion/detorsion in rats. Journal of Applied Pharmaceutical Science. 6(2): 135140.

Aebi, H.E. (1983). Catalase. In: Methods of Enzymatic Analysis. [Bergmeyer, H.U. (ed)], Verlag Chemie Weinham, Germany, (p. 273-286).

Akcoora, B., Altug, M.E., Balci, A., Hakverdi, S., Yonden, Z., Akbas, O.A., Karazincir, S. and Ozyurt, H. (2008). Gradual detorsion of torsioned rat testis attenuates ischemia/ perfusion injury. Journal of Pediatric Surgery. 43: 18791884. 
Evaluation of Combined Effects of Vitamin E and Methylprednisolone in Ischemia and Reperfusion Injury of the Testicle...

Alper, B., Murat, U., Gokhan, C., Mehmet, T., Metin, K., Ibrahim, A. and Huseyin, C. (2016). Effects of individual or combined use of alpha-lipoic acid and methylprednisolone on malondialdehyde, superoxide dismutase and catalase level in acute spinal cord injury in rat. Journal of Health Science. 6(3): 174-183.

Colombo, N.B.R., Rangel, M.P., Martins, V., Hage, N. and Capelozzi, C.K. (2010). Caryocar brasilliese Comb protects against genomic and oxidative damage in urethane-induced lung carcinogenesis. Brazillian Journal of Medical and Biological Research. 48(9): 852-862.

Filho, D.W., Torres, M.A., Bordin, A.L., Crezcynski-Pasa, T.B. and Boveris, A. (2004). Spermatic cord torsion, reactive oxygen and nitrogen species and ischemia - perfusion injury. Molecular Aspects of Medicine. 11: 159-164.

Flohe, L. and Gunzler, W.A. (1984). Assays of Glutathione Peroxidase. In: Methods in Enzymology, Volume 105: Oxygen Radicals in Biological Systems, Packer, L. and A.N. Glazer (Eds.). Academic Press, New York, USA., ISBN-13: 978-0-12182005-3, pp: 114-121.

Gaspareto, C., Malinverno, A., Gulacciati, D., Gritti, D., Prossperini, P.G., Specchia, G. and Icevuti, G. (2005). Anti-oxidant vitamins reduce oxidative stress and ventricular remodelling in patient with acute myocardial infarction. International Journal of Immunopathology and Pharmacology. 18: $487-97$

Hekimoglu, A., Kurcer, Z., Aral, F., Baba, F., Sahna, E. and Atessahin, A. (2009). Lycopene, an antioxidant carotenoid, attenuates testicular injury caused by ischemia/perfusion in rats. Tohoku Journal of Experimental Medicine. 218: 141-147.

Jain, S.K., McVie, R., Duet, J. and Herbert, J. (1989). Erythrocyte membrane lipid peroxidation and glycolyted hemoglobin in diabetes. Diabetes. 38: 1539-1543.

Karaguzel, E. (2014). Comparison of the protective effect of dipyridamole and acetylsalicylic acid on long term histologic damage in a rat model of testicular ischemia/perfusion injury. Journal of Pediatric Surgery. 47: 1716-1723.
Koupparis, A.J., Jeremy, J.Y., Muzaffar, S., Persad, R. and Shukla, N. (2005). Sildenafil inhibits the formation of superoxide and the expression of gp47 $\mathrm{NAD}(\mathrm{P}) \mathrm{H}$ oxidase induced by the thromboxane A2 mimetic, U46619, in corpus cavenosal smooth muscle cells. British Journal of Urology International. 96: 423-427.

Lowry, O.H., Rosebrough, N.J., Farr, A.L. and Randall, R.J. (1951). Protein measurement with the folin phenol reagent. Journal of Biological Chemistry. 193: 265-267.

Magwere, T., Naik, Y.S. and Hasler, Y.S. (1997). Effects of chloroquine treatment on antioxidant enzymes in rat liver and kidney. Free Radical Biology and Medicine. 22(1-2): 321-327.

Maxwell, S.R. (1995). Prospects for the use of antioxidant therapies. Drugs. 49: 345-361.

Osmanagaoglu, M.A., Kesim, M., Yulug, E., Mentede, A. and Karahan, C.S. (2012). The effect of high dose of methylprednisolone on experimental ovarian torsion/reperfusion injury in rats. Geburstshilfe Frauenheilk. 72: 70-74.

Reaume, A.G., Elliot, J.T., Hoffman, E.K., Kowall, N.W., Ferrante, R.J., Siwek, D.F. and Snider, W.D. (1996). Motor neurons in $\mathrm{Cu} / \mathrm{Zn}$ superoxide dismutase-deficient mice develop normally but exhibit enhanced cell death after axonal injury. Nature Genetics. 13: 43-47.

Reaven, P. (1995). Dietary and pharmacologic regimens to reduce lipid peroxidation in non-insulin-dependent diabetes mellitus. American Journal of Clinical Nutrition. 62: 1483-1489.

Salmasi, A.H., Beheshtian, A., Payabvash, S., Demehri, S., Ebrahimkhani, M.R., Karimzadegan, M. and Dehpour, A.R. (2005). Effect of morphine on ischemia-perfusion injury: Experimental study in testicular torsion rat model. Urology. 66: 13381342.

Salvemini, D., Wang, Z. Q., Zweier, J. L., Samouilov, A., Macarthur, H., Misko, T.P. and Riley, D.P.A. (1999). Non peptidyl mimic of superoxide dismutase with therapeutic activity in rats. Science. 286: 304-306.

Slivka, A.P. and Murphy, E.J. (2001). High dose methylprednisolone treatment in experimental focal cerebral ischemia. Experimental Neurology. 167: 166-72. 